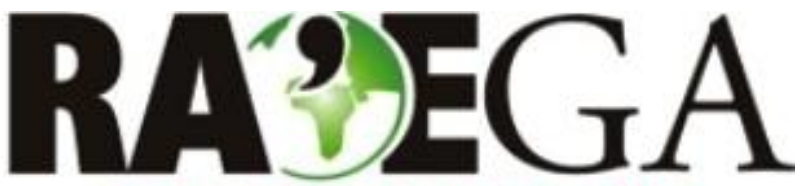

O ESPACO GEOGRÁFICO EM ANÁLISE

\title{
ZONEAMENTO AMBIENTAL COMO SUBSÍDIO PARA O ORDENAMENTO DO TERRITÓRIO DA BACIA HIDROGRÁFICA DO RIO SALOBRA, SERRA DA BODOQUENA - MS
}

\section{ENVIRONMENTAL ZONING AS SUBSIDY FOR ORDINANCE OF THE TERRITORY OF THE WATERSHED OF SALOBRA RIVER - BODOQUENA PLATEAU, MATO GROSSO DO SUL STATE}

\author{
João Cândido André da Silva Neto \\ Professor da Universidade do Estado do Amazonas (UEA) \\ Centro de Estudos Superiores de Tefé \\ Tefé, $A M$ \\ e-mail: joaokandido@yahoo.com.br
}

Recebido em: 12/09/2013

\section{Resumo}

A proposta do zoneamento ambiental corresponde a um instrumento que se opõe ao ideal do modelo desenvolvimentista, caracterizado por intensa atuação das políticas governamentais centralizadas e progressistas que não reconhecem as diferenciações e vulnerabilidades observadas em cada paisagem. Nessa perspectiva, o presente artigo tem o objetivo de discutir uma proposta de zoneamento ambiental na bacia hidrográfica do rio Salobra, a qual baseou-se na metodologia de Crepani et al. (2008), para avaliar a vulnerabilidade da paisagem, e da proposta metodológica de Becker e Egler (1996), para elaboração do zoneamento ambiental, tendo como base os aspectos físico-naturais da paisagem, com a finalidade de apontar as possíveis rupturas desencadeadas pelo uso inadequado da terra. Foram processadas Imagens de Satélites, dados de modelos numéricos de terreno, vetoriais e matriciais utilizando Sistema de Informação Geográfica (SIG). O SIG possibilitou a implementação da análise espacial, cujo suporte à decisão permitiu a combinação e correlação de diferentes planos de informações, resultando em modelos e cenários da relação das variáveis analisadas. A partir do zoneamento ambiental verificou-se que maior parte da área da bacia hidrográfica do rio Salobra apresentou limitantes físico-ambientais que restringem ou impossibilitam alguns tipos de uso da terra, como as áreas de Conservação com $37 \%$, Preservação Prioritária 40\% e Preservação/Recuperação $2 \%$. Conclui-se que o zoneamento ambiental possibilitou identificação de áreas que se adequam a cada lugar segundo suas condições específicas, auxiliando a implementação de políticas de planejamento e gestão do uso da terra na área de estudo. 
Palavras-chave: Sistemas de Informações Geográficas, Vulnerabilidade à perda de solos, Zoneamento Ambiental, Serra da Bodoquena.

\begin{abstract}
The proposed environmental zoning corresponds to an instrument which opposes the ideal developmental model, characterized by intense performance of centralized government and progressive policies that do not recognize the differences and vulnerabilities observed in each landscape.In this perspective, this paper has the objective of discuss a proposal for environmental zoning in watershed of Salobra river, which was based on the methodology Crepani et al. (2008) to evaluate the vulnerability of the landscape, and the proposed methodology of Becker and Egler (1996), for the elaboration of environmental zoning, based on the physical-natural landscape, with the purpose of point out the possible disruptions triggered by inappropriate land use.Were processed satellite images, data numerical models of land, vectorial and matrix utilizing the Geographic Information Systems (GIS). The GIS enabled the implementation of the spatial analysis, decision support which allowed the combination and correlation of different plans information, resulting in models and scenarios of the relationship of the variables analyzed.From of the environmental zoning was found that majority of the area of the watershed of Salobra river presented limiting physical environment that restrict or make impossible some types of land use, such as Conservation Areas with 37\%, Preservation Priority 40\% and Preservation / Recovery $2 \%$. It is concluded that the environmental zoning allowed identification of areas that suit each place according to their specific conditions, assisting the implementation of planning policies and management of land use in the study area.
\end{abstract}

Keywords: Geographic Information Systems, Vulnerability loss of soil, Environmental Zoning, Bodoquena Plateau.

\title{
INTRODUÇÃO
}

A intensificação dos processos de degradação ambiental está frequentemente associada aos usos inadequados da terra, que normalmente ocorrem sem o conhecimento prévio da área utilizada. Nesse processo de apropriação da natureza qualquer área pode ser explorada, desrespeitando assim os limitantes físico-naturais das paisagens.

As áreas de incompatibilidade do uso da terra correspondem às áreas utilizadas de maneira inadequada para desenvolvimento das atividades como a pecuária e agricultura, onde não são respeitadas as limitações físico-naturais de ambientes vulneráveis, como exemplo, áreas com relevo fortemente dissecado ou áreas de solos rasos suscetíveis à erosão. 
ZONEAMENTO AMBIENTAL COMO SUBSÍDIO PARA O ORDENAMENTO DO TERRITÓRIO DA BACIA HIDROGRÁFICA DO RIO SALOBRA, SERRA DA BODOQUENA - MS

Esse cenário é visualizado de modo cada vez mais frequente, visto que, historicamente no território brasileiro, vem sendo imposto um processo de apropriação da natureza, de uma maneira em que esta é concebida apenas como uma mercadoria. Logo, passível de uma superexploração, de forma inconsequente e sem planejamento.

Destaca-se que na área abordada apresente uma configuração de paisagens vulneráveis, na qual alguns tipos de usos da terra podem desencadear os processos de degradação dessa paisagem. Uma porção significativa da bacia hidrográfica do rio Salobraé caracterizada como um ambiente vulnerável de acordo com suas características físico-ambientais (SILVA NETO, 2012).

Justifica-se o presente estudo por abordar uma área que ainda há uma grande carência de informações e estudos que possibilitem um diagnóstico cuidadoso, que permita fazer as devidas restrições e indicações de usos adequados para a área.

Portanto, ressalta-se a necessidade de se conhecer melhor a dinâmica e limitações dessa área, para se estabelecer perspectivas de utilização, manejo, medidas conservacionistas dos recursos naturais e, se fazer restrições mais seguras quanto ao uso da terra.

Nessa perspectiva, a hipótese do presente estudo supõe que o ambiente abordado apresenta uma porção significativa de sua área condicionada à tipos de usos da terra incompatíveis com as características naturais da área, possibilitando condições de degradação dessa paisagem.

Assim, o objetivo central do presente artigo foi elaborar uma proposta de zoneamento ambiental da bacia hidrográfica do rio Salobra tendo como base os aspectos físico-naturais da paisagem, visando analisar os processos de degradação dos recursos ambientais decorrentes do uso inadequado da terra, manifestado no processo de apropriação da área.

Nessa perspectiva, o Zoneamento Ambiental é apresentado como uma proposta para amenizar as rupturas desencadeadas pela atuação da sociedade na natureza, enfatizando uma nova organização das formas espaciais que se materializam na paisagem. 
ZONEAMENTO AMBIENTAL COMO SUBSÍDIO PARA O ORDENAMENTO DO TERRITÓRIO DA BACIA HIDROGRÁFICA DO RIO SALOBRA, SERRA DA BODOQUENA - MS

\section{REVISÃO BIBLIOGRÁFICA}

Para elaboração a base teórica do presente artigo foram consultados os trabalhos de Becker e Egler (1996), Ross (2006), Guimarães e Santos (2007), Silva (2008), Cunico e Oka-Fiori (2008), Schirmer e Robaina (2012), Rodrigues (et al. 2001), Oliveira (et al. 2009), Thomas (2012), Melo e Lima (2012), Neves (et al.2011) e Mesquita (et al.2011), que abordaram temas como zoneamento ambiental, vulnerabilidade ambiental e perda de solos e erosão.

Foram analisados os diferentes procedimentos metodológicos utilizados nos trabalhados citados, além da definição de zoneamento ambiental como um instrumento que se opõe ao ideal do modelo desenvolvimentista, caracterizado por intensa atuação das políticas governamentais centralizadas e progressistas que não reconhecem as diferenciações e vulnerabilidades observadas em cada paisagem.

Na mesma perspectiva Ross (2006) expôs que:

As proposições de zoneamento ambiental devem refletir a integração das disciplinas técnico-científicas na medida em que consideram as potencialidades do meio natural, adequando os programas de desenvolvimento e os meios institucionais a uma relação harmônica entre sociedade e natureza, cujo princípio básico é o ordenamento do território calcado nos pressupostos do desenvolvimento com política conservacionista. (ROSS, 2006, p.149).

A proposta metodológica de zoneamento, elaborado por Becker e Egler (1996), é definida como um instrumento político e técnico do planejamento cuja finalidade é otimizar o uso do espaço e as políticas públicas, e não deve ser entendido como um instrumento apenas corretivo, mas também ativo no processo de apropriação da natureza.

Esse processo de re-organização das formas criadas pelo homem a partir da relação da apropriação da natureza estabelece outro processo, que segundo Leff (2006) seria a reapropriação social da natureza.

Para Becker e Egler (1996) o zoneamento ambiental representa um novo modelo de produzir baseado no conhecimento e na informação, que atribui outro significado à natureza que passa ser vista como um bem escasso, por isso, se valoriza como capital. 
O zoneamento ambiental é entendido como um pilar essencial nas bases de ordenamento do território, no qual a partir das propostas elaboradas pelo zoneamento ambiental, objetiva-se alcançar as diretrizes que o subsidiem.

Nesse sentido ordenar o território constitui o processo de re-apropriação das suas bases, cujo objetivo essencial é buscar a melhor disposição dos elementos nele contido.

Assim, o ordenamento do território é um instrumento fundamental ao tratarse das diferenças de cada lugar, cujo objetivo principal constituem-se na definição de transformações, técnicas e ritmos que se adequam a cada lugar segundo suas condições específicas. (BECKER e EGLER 1996).

Desse modo os pressupostos teórico-metodológicos devem conduzir o desenvolvimento dos trabalhos que objetivem a proposta de estruturação de medidas capaz de nortear "as atividades econômicas e as ações de ordenamento do territorial, envolvendo a articulação institucional dos diferentes agentes promotores e modificadores do meio ambiente." (ROSS, 2006, p.151).

Para Vallejo (2009) o zoneamento é um instrumento de ordenamento territorial utilizado para se conseguirem determinados resultados no manejo de uma unidade da paisagem, estabelecendo usos diferenciados para cada zona, conforme aptidão físico-natural e socioeconômica de cada zona.

O zoneamento ambiental é composto por um conjunto de diretrizes, atividades, e medidas que visam propor a organização de uma determinada região, tendo em vista o uso adequado dos recursos ambientais, de modo a atender as demandas socioeconômicas das populações locais, bem como as demandas de conservação ambiental.

Nesse contexto, o zoneamento deve propor diretrizes, no qual as potencialidades e a taxa de resiliência do ecossistema deveriam determinar a capacidade de exploração econômica dos recursos naturais dentro de diferentes racionalidades produtivas estabelecendo, assim, as condições do meio para a regeneração dos ecossistemas explorados.

O objetivo do zoneamento ambiental é definido para ponderar e projetar o uso da terra, diretrizes considerando primordialmente as características que englobam a vulnerabilidade natural da paisagem, a aptidão agrícola dos solos, as 
áreas de preservação permanente (APP), considerando-se ainda as atividades econômicas e sociais que se manifestam nos tipos de usos da terra de uma determinada região.

Leff (2006) destacou a importância do zoneamento ambiental como um instrumento a serviço da racionalidade ambiental, confrontando a hegemonia da racionalidade econômica. Considerando ainda que a racionalidade ambiental propõe novas perspectivas para as forças produtivas por meio do ordenamento ecológico, da distribuição territorial e da reorganização social das atividades produtivas.

\section{CARACTERIZAÇÃO DA ÁREA}

A presente proposta abordou como objeto de estudo a bacia hidrográfica do rio Salobra, localizada na região Sudoeste do Estado de Mato Grosso do Sul,estendendo-se pelos municípios de Bonito (nascente), Bodoquena (maior parte da extensão de sua rede de drenagem) e Miranda (baixo curso e foz), com área de aproximadamente $2.350 \mathrm{~km}^{2}$, considerada uma das principais áreas fontes de fluxos de matéria e energia para bacia do Rio Miranda no Pantanal sul-mato-grossense (Figura 1).

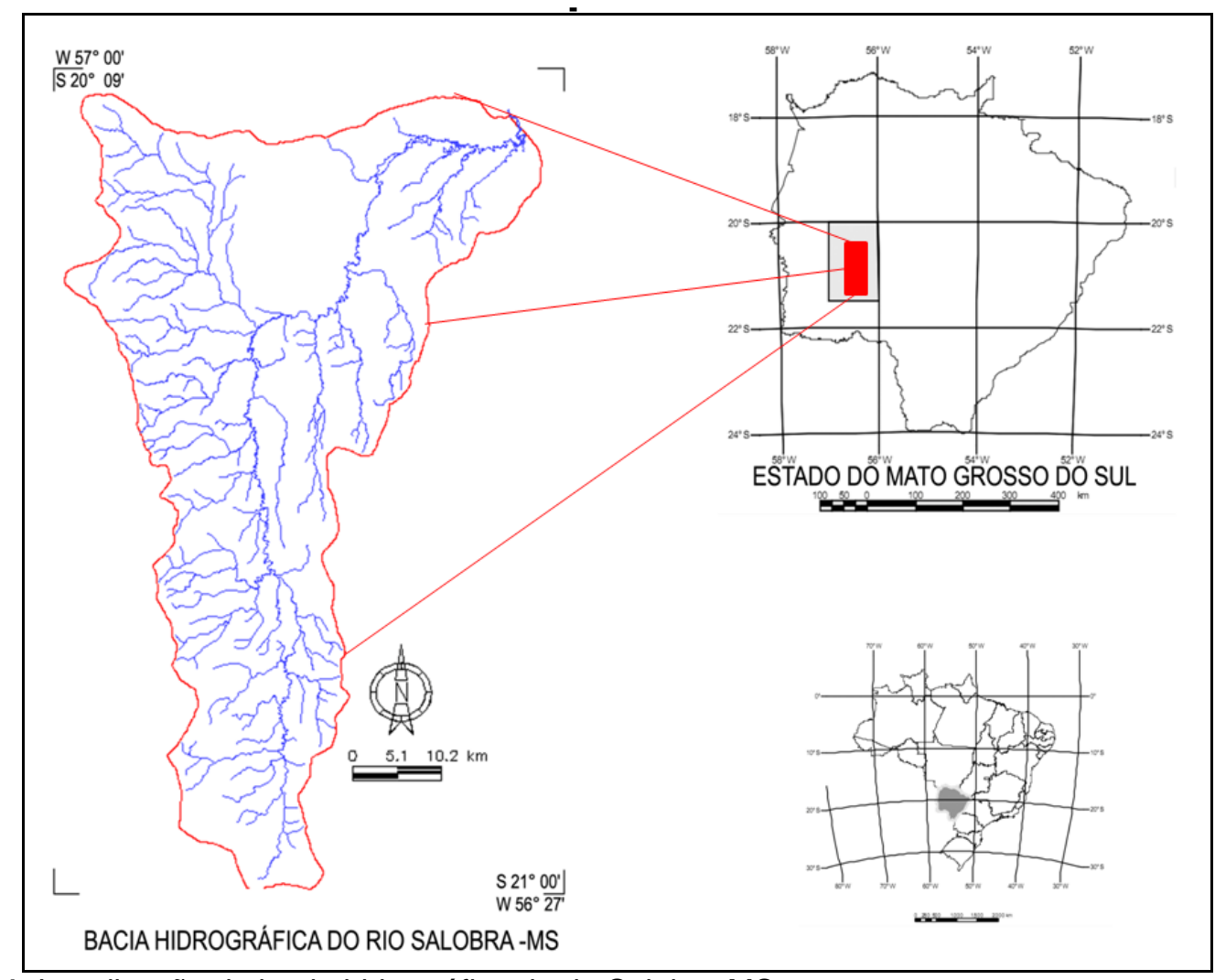

Figura 1: Localização da bacia hidrográfica do rio Salobra-MS. 
A bacia hidrográfica do rio Salobra está inserida na área proposta do Geopark da Serra da Bodoquena e Pantanal apresentada à UNESCO. Essa proposta diferencia-se das Unidades de Conservação tradicionais e deve-se principalmente às particularidades geológicas da área, como por exemplo, as tufas calcárias verificadas ao longo da rede de drenagem da bacia hidrográfica do rio Salobra.

Segundo estudos de Araújo et al. (1982) apresentado no Projeto RADAMBRASIL e Lacerda Filho et al. (2006) apresentado no relatório de Geologia e Recursos Minerais do Estado de Mato Grosso do Sul, a área da bacia hidrográfica do rio Salobra, apresenta-se estruturada litologicamente sobre o arcabouço geológico da Formação Cerradinho e Formação Bocaina, rochas do Pré-cambriano Superior e, Formação Pantanal do período Quaternário. Verifica-se também a ocorrência de rochas do Grupo Cuiabá e Formação Puga (Tabela 1).

Tabela 1: Unidades litológicas da bacia hidrográfica do rio Salobra-MS.

\begin{tabular}{l|c|c}
\multicolumn{1}{c|}{ Litologias } & Área em $\mathbf{K m}^{\mathbf{2}}$ & Área em \% \\
\hline Depósitos aluvionares (Q1p2) & 141,09 & 6 \\
Terraços aluvionares (Q1p1) & 336,95 & 14 \\
Formação Cerradinho (NP3ce-c) & 106,27 & 5 \\
Formação Cerradinho (NP3ce-d) & 258,97 & 11 \\
Subunidade Pelítica (NPcuxt) & 136,64 & 6 \\
Subunidade Pelítica (NPcufl) & 158,63 & 7 \\
Subunidade Carbonática (NPcum) & 170,42 & 7 \\
Formação Puga (NPpu) & 14,76 & 1 \\
Formação Bocaina & 988,06 & 43 \\
\hline
\end{tabular}

Almeida (1965) considerou o Planalto da Bodoquena a mais importante feição geomorfológica da região Sudoeste do Mato Grosso do Sul, não só por suas elevações de altitude do relevo, como por sua extensão, que assume um formato estreito e longo de planalto composto por calco-dolomítico.

No limite Norte da Serra da Bodoquena ocorre o recobrimento dos sedimentos cenozóicos da Formação Pantanal e ao Sul praticamente desaparece, ocorrendo apenas alguns morros isolados em calcários do Grupo Itapucumi.

A principal característica pedológica da bacia hidrográfica do Rio Salobra é a presença de solos provenientes das formações geológicas citadas anteriormente, onde suas litologias variam desde as originadas de calcários, ardósias do pré- 
ZONEAMENTO AMBIENTAL COMO SUBSÍDIO PARA O ORDENAMENTO DO TERRITÓRIO DA BACIA HIDROGRÁFICA DO RIO SALOBRA, SERRA DA BODOQUENA - MS

cambriano (Grupo Corumbá), até os sedimentos mais recentes da Formação Pantanal(Tabela 2).

Tabela 2: Tipos de solos e índice de vulnerabilidade à perda de solos na bacia hidrográfica do rio Salobra-MS.

\begin{tabular}{l|c|c}
\hline \multicolumn{1}{c|}{ Tipos de solos } & Área em $\mathbf{~ k m}^{\mathbf{2}}$ & Área em \% \\
\hline Planossolos Nátricos & 127,23 & 6 \\
Planossolos Hidromórficos & 70,3 & 3 \\
Nitossolos & 346,68 & 15 \\
Chernossolos Argilúvicos & 141,08 & 6 \\
Luvissolos & 124,66 & 5 \\
Gleissolos & 56,19 & 2 \\
Vertissolos & 245,44 & 11 \\
Chernossolos Rêndzicos & 1092,24 & 47 \\
Neossolos Litólicos & 49,78 & 2 \\
Neossolos Regolíticos & 69,2 & 3 \\
\hline
\end{tabular}

Outro contraste é quanto ao relevo onde alguns tipos de solos são encontrados, pois variam desde relevo plano até fortemente dissecado. O tipo de solo de maior expressão com relação à área ocupada na bacia do rio Salobra é dos Chernossolos Rêndzicos, característico das áreas com relevo fortemente ondulado. Grande parte destes solos são utilizados para pecuária, a principal atividade econômica da região.

\section{MATERIAIS E MÉTODOS}

Elaborou-se um banco de dados em ambiente de SIG, divididos em modelo temáticos, imagem e modelo numérico do terreno, com estrutura de dados matricial (raster) e vetorial.

Para caracterização dos planos de informações, foram consultados materiais como projeto RADAMBRASIL, Mapa geológico do Estado do Mato Grosso do Sul, PCBAP (Plano de Conservação da Bacia do Alto Paraguai) e realizadas verificações a campo, onde foram averiguadas as unidades litológicas, as formas e características do relevo, dos tipos de solos e dos usos da terra.

O primeiro passo consistiu na organização e edição das bases cartográficas das unidades litológicas e tipos de solos. Essas informações foram compiladas em ambiente de SIG, no software SPRING. 
Conforme proposta de Crepani (2008) foram produzidos mapas de intensidade pluviométrica a partir de dados das estações pluviométricas, com tratamento estatístico e processamento em SIG.

Elaborou-se o mapa de vulnerabilidade do relevo, tendo como base os dados das imagens SRTM/ Topodata, no qual foram combinados PI's de formas do terreno, hipsometria e declividade.

Para elaboração dos mapas de uso da terra e cobertura vegetal utilizou-se imagens de satélite Landsat 2 MSS e Landsat $5 \mathrm{TM}$, processadas utilizando 0 classificador supervisionado Bhattacharya.

Optou-se pelo classificador Bhattacharya, por não ser um classificador automático e requerera interação do usuário, através do treinamento esuas amostras são as regiões formadas na segmentação de imagens. Neste classificador se mede a distância média entre as distribuições de probabilidades de classes espectrais(SAMPAIO LOPES, 2012).

Nos procedimentos metodológicos utilizou-se aanálise espacial como ferramenta para análise da paisagem, enfatizando-se em sua aplicabilidade como aporte para análise ambiental, tendo como objetivo central estabelecê-la como suporte técnico-operacional na reflexão teórica da perspectiva da análise integrada da paisagem.

A metodologia utilizada na presente pesquisa está baseada na proposta por Becker e Egler (1996) de Zoneamento Ecológico-Econômico, e de vulnerabilidade da paisagem à perda de solos proposta por Crepani et al. (2008).

Desse modo foram abordadas as seguintes variáveis da bacia hidrográfica para elaboração do mapa de vulnerabilidade das paisagens à perda de solos (Figura 2):

Vulnerabilidade dos solos (Níveis de erodibilidade dos solos, Fonte: Projeto RadamBrasil, na escala 1: 1.000.000);

> Vulnerabilidade da intensidade pluviométrica (dados de intensidade pluviométrica $\mathrm{mm} / \mathrm{mês}$; Fonte: hidroweb, dez estações na região);

> Vulnerabilidade do relevo (cruzamento dos P.I. declividade + hipsometria + formas do terreno; Fonte: dados SRTM/ TOPODATA, resolução espacial de 30 metros); 
ZONEAMENTO AMBIENTAL COMO SUBSÍDIO PARA O ORDENAMENTO DO TERRITÓRIO DA BACIA HIDROGRÁFICA DO RIO SALOBRA, SERRA DA BODOQUENA - MS

> Vulnerabilidade litológica (Resistência das rochas que compõem cada unidade litológica; Fonte: Projeto RadamBrasil, na escala 1:1.000.000, apoiado no Mapa geológico do Mato Grosso do Sul de 2006 na escala $1: 1.000 .000)$;

Vulnerabilidade da cobertura vegetal e uso da terra (Fonte: Imagens Landsat 2 MSS e 5 TM, resolução espacial de 30 metros).

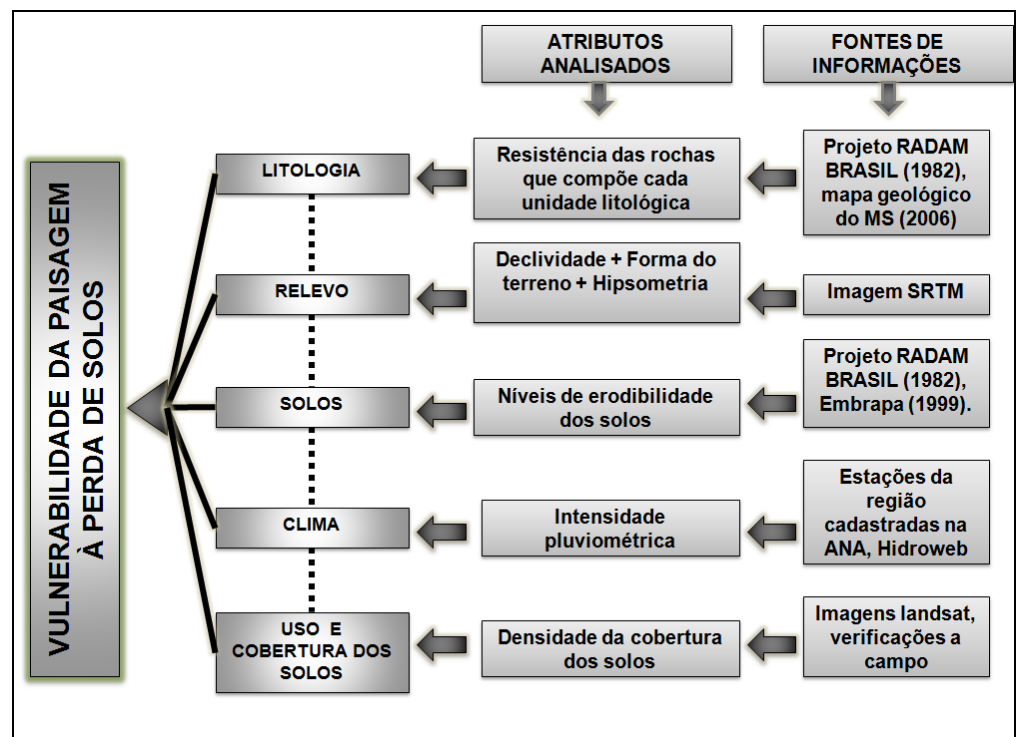

Figura 2: Organograma para elaboração da vulnerabilidade da paisagem à perda de solos. Fonte: SILVA NETO, 2012.

Quanto aos pesos dos atributos de cada variável, utilizou-se a proposta de Zoneamento Ecológico-econômico elaborada por Crepani et al. (2008), na qual foi adaptada para implementação do método AHP, variando de 0,0 a 1,0 (Quadro 1). 
ZONEAMENTO AMBIENTAL COMO SUBSÍDIO PARA O ORDENAMENTO DO TERRITÓRIO DA BACIA HIDROGRÁFICA DO RIO SALOBRA, SERRA DA BODOQUENA - MS

\begin{tabular}{|c|c|c|c|}
\hline TIPOS DE SOLOS & $\begin{array}{c}\text { Indice de } \\
\text { Vulne rabilidade } *\end{array}$ & VULNERAB ILIDADE DO RELEVO & \begin{tabular}{|c|} 
Indice de \\
Vulne rabilidade*
\end{tabular} \\
\hline Planossolos Nátricos & 0,40 & Muito Fraca & 0,20 \\
\hline Planossolos Hidromórficos & 0,40 & Fraca & 0,40 \\
\hline Nitossolos & 0,40 & Moderada & 0,60 \\
\hline Chernossolos Argilúvicos & 0,40 & Forte & 0,80 \\
\hline Luvissolos & 0,40 & Muito Forte & 1,00 \\
\hline Gleissolos & 1,00 & USO DA TERRA & \\
\hline Vertissolos & 1,00 & Áreas Úmidas & 0,33 \\
\hline Chernossolos Rêndzicos & 1,00 & Mata & 0,46 \\
\hline Neossolos Litólicos & 1,00 & Pastagem & 0,83 \\
\hline Neossolos Regolíticos & 1,00 & Plantação & 0,90 \\
\hline UNIDADES LITOLÓGICAS & & Solo exposto / afloramento rochoso & 1,00 \\
\hline Depósitos aluvionares (Q1p2) & 1,00 & INTENSIDADE PLUVIOMÉTRICA & \\
\hline Terraços aluvionares (Q1p1) & 1,00 & 375 a $400 \mathrm{~mm} / \mathrm{mês}$ & 0,70 \\
\hline Formação Cerradinho (NP3ce -c) & 0,80 & 400 a 425 mm/mês & 0,75 \\
\hline Formação Cerradinho (NP3ce -d) & 0,80 & 425 a $450 \mathrm{~mm} / \mathrm{mês}$ & 0,80 \\
\hline Subunidade Pelítica (NPcuxt) & 0,60 & 450 a $475 \mathrm{~mm} / \mathrm{mês}$ & 0,85 \\
\hline Subunidade Pelítica (NPcufl) & 0,60 & 475 a 500 mm/mês & 0,90 \\
\hline Subunidade Carbonática (NPcum) & 0,50 & 500 a $525 \mathrm{~mm} / \mathrm{mês}$ & 0,95 \\
\hline Formação Puga (NPpu) & 0,50 & $>525 \mathrm{~mm} / \mathrm{mês}$ & 1,00 \\
\hline Formação Bocaina & 0,05 & \multicolumn{2}{|c|}{ * Adaptado de Crepani et al. 2008} \\
\hline
\end{tabular}

Quadro 1: Peso dos atributos adaptado para implementação de método AHP:

Cabe enfatizar que a atribuição dos pesos para as variáveis utilizando o método AHP,ocorreu após a elaboração de vários modelos experimentais, nosquais foram conferidos em campo, sendo escolhido o modelo que mais aproximou-se da realidade observada na área de estudo.

Desse modo, para elaboração do mapa de vulnerabilidade natural da paisagem correlacionou-se as variáveis de vulnerabilidade do relevo e tipos de solos, nas quais foram atribuídas peso 4 que corresponderiamas variáveis mais influentes, seguido pelas unidades litológicas, em que atribuiu-se o peso 2, para intensidade pluviométrica atribuiu-se o peso 1, que corresponderia à variável menos influente na presente análise (Quadro 2, em vermelho o programa válido).

Quadro 2: Pesos utilizados nos planos de informações testes

\begin{tabular}{|l|c|c|c|c|c|c|c|c|}
\hline Plano de Informação & Litologia & peso & Solo & peso & Geomorf & peso & Intens. Pluvi. & peso \\
\hline Vulnerabilidade_natu1 & 0,167 & 1 & 0,333 & 2 & 0,333 & 2 & 0,167 & 1 \\
\hline Vulnerabilidade_natu2 & 0,141 & 1 & 0,263 & 2 & 0,455 & 3 & 0,141 & 1 \\
\hline Vulnerabilidade_natu3 & 0,141 & 1 & 0,455 & 3 & 0,263 & 2 & 0,141 & 1 \\
\hline Vulnerabilidade_natu4 & 0,141 & 1 & 0,263 & 2 & 0,455 & 3 & 0,141 & 1 \\
\hline Vulnerabilidade_natu5 & 0,143 & 2 & 0,385 & 4 & 0,385 & 4 & 0,087 & 1 \\
\hline Vulnerabilidade_natu6 & 0,200 & 1 & 0,200 & 1 & 0,400 & 2 & 0,200 & 1 \\
\hline Vulnerabilidade_natu7 & 0,571 & 4 & 0,143 & 1 & 0,143 & 1 & 0,143 & 1 \\
\hline
\end{tabular}


O mapa de vulnerabilidade da paisagem à perda de solos resultou da combinação dos P.I.s de uso da terra e cobertura vegetal com vulnerabilidade natural à perda de solos.

O mapa síntese de zoneamento ambiental seguiu os procedimentos operacionais da análise espacial em SIG, como a álgebra de mapas, utilizando-se operadores booleanos nas análises qualitativas para geração da informação temática.

O Zoneamento Ecológico-Econômico proposto por Crepani et al. (2008) apoiou-se na correlação de variáveis da vulnerabilidade da paisagem à perda de solos, Áreas de Preservação Permanente, Uso e cobertura da terra. Essas correlações de variáveis sustentaram as propostas de zoneamento ambiental na bacia hidrográfica do rio Salobra (Figura 3).

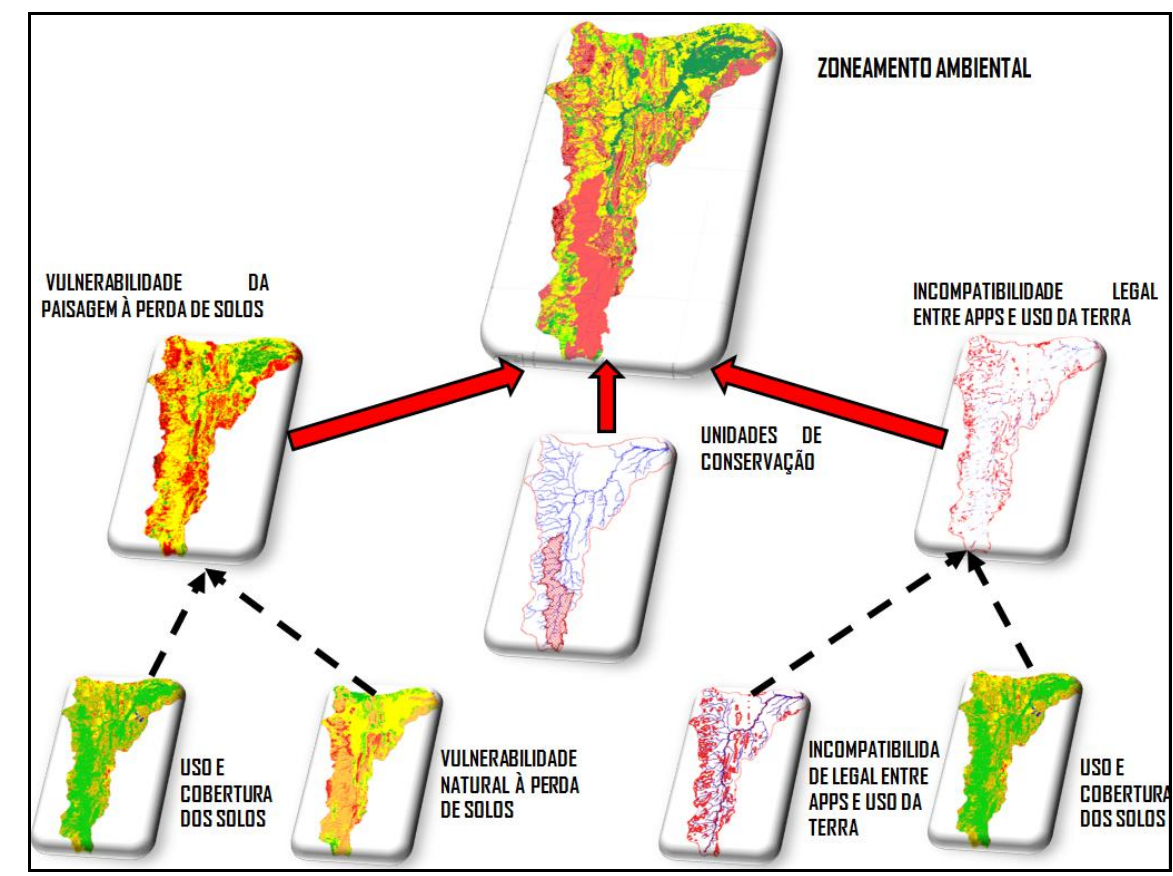

Figura 3: Organograma das correlações de variáveis para elaboração do mapa de zoneamento ambiental da bacia hidrográfica do rio Salobra.

As áreas para zoneamento ambiental foram definidas de acordo com a atual conjuntura da paisagem da bacia hidrográfica do rio Salobra, que resulta das diversas inter-relações com o uso da terra e associado a outras variáveis que podem comprometer em diferentes níveis as dinâmicas da área, no qual os processos erosivos são destacados na presente proposta como principal problema de ordem 
ZONEAMENTO AMBIENTAL COMO SUBSÍDIO PARA O ORDENAMENTO DO TERRITÓRIO DA BACIA HIDROGRÁFICA DO RIO SALOBRA, SERRA DA BODOQUENA - MS

ambiental e apresenta uma relação direta com a cobertura vegetal e, sua retirada para práticas agropecuárias torna esses processos mais intensos (Quadro 3).

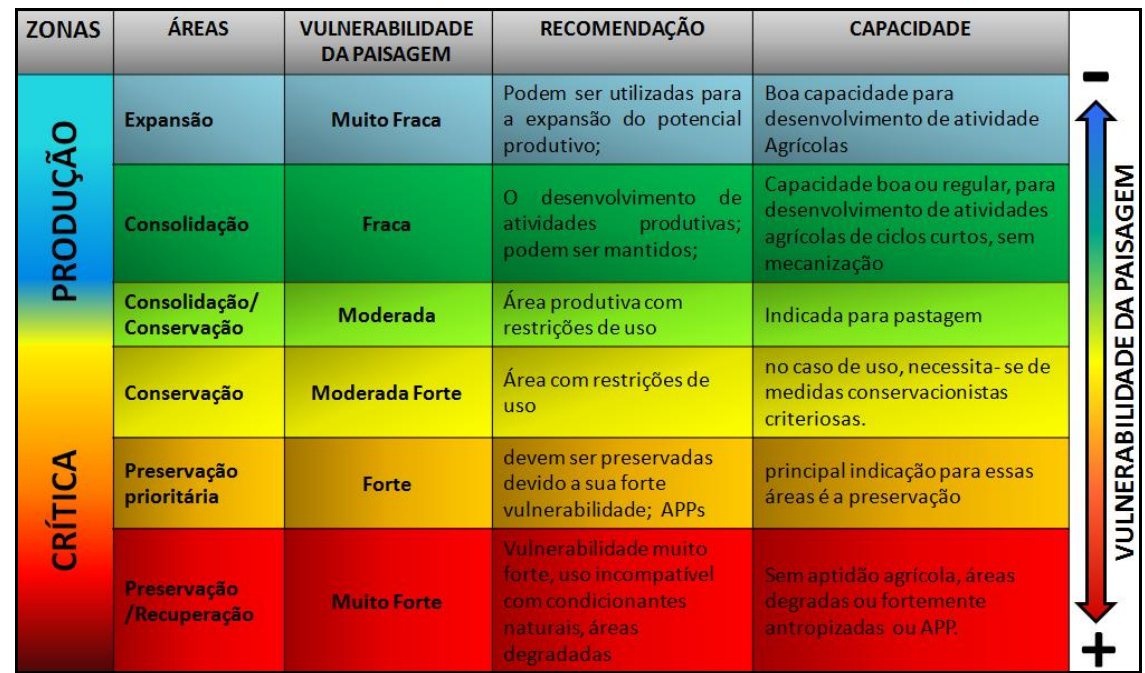

Quadro 3: Relação vulnerabilidade da paisagem à perda de solos e zoneamento ambiental.

As zonas ambientais são definidas a partir de condicionantes físico-naturais, vulnerabilidade da paisagem à perda de solos, áreas institucionais e áreas que manifestam os processos de apropriação da natureza por meio do uso da terra.

\section{RESULTADOS E DISCUSSÕES}

De acordo com a análise da vulnerabilidade da paisagem à perda de solos no ano de 2009, verificou-se que 33\% da área estudada se enquadram nas classes de vulnerabilidadeforte e muito forte, que representam as áreas que estão mais vulneráveis à desencadear os processos erosivos potencializados por usos inadequados da terra, estas classes também podem ser definidas como ambientes Instáveis (Figura 4). 
Figura 4: Vulnerabilidade da paisagem à perda de solos na bacia hidrográfica do Rio Salobra - MS em 2009.

A classe vulnerabilidade moderadacaracteriza-se por apresentar ainda cobertura vegetal capaz de proteger o solo do aceleramento dos processos erosivos, verificada em $56 \%$ da área da bacia, esta é uma classe intermediária entre os ambientes instáveis e os ambientes estáveis, e podem caracterizar-se como áreas que apresentam os condicionantes físicos de paisagens vulneráveis/instáveis e paisagens estáveis normalmente, o uso da terra é compatível com esses limitantes físicos (Figura 5).

Os ambientes estáveis estão representados na presente análise pelas classes Fraca, que ocupou 23\% da área total da bacia do rio Salobra, e Muito Fraca, que não apresentou porções representativas da área estuda nos dois anos analisados.

Esses ambientes estáveis caracterizam-se por apresentar áreas que correlacionam-se cobertura vegetal densa, relevo plano ou suave a ondulado, rochas coesas, pouco alteradas, associados à solos profundos e bem desenvolvidos. 


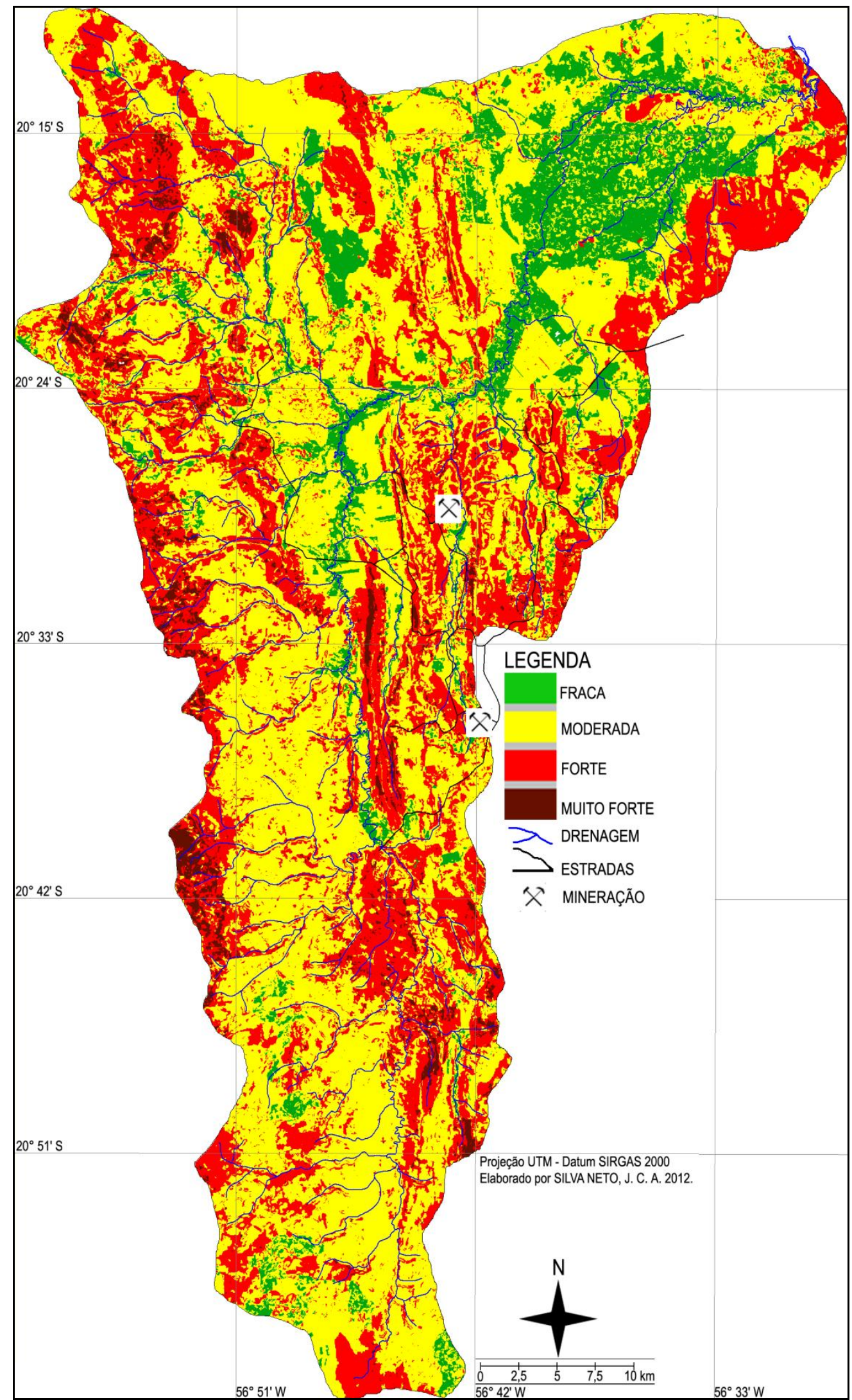

Figura 5: Vulnerabilidade da paisagem à perda do solo da bacia hidrográfica do rio Salobra-MS em 2009. 
ZONEAMENTO AMBIENTAL COMO SUBSÍDIO PARA O ORDENAMENTO DO TERRITÓRIO DA BACIA HIDROGRÁFICA DO RIO SALOBRA, SERRA DA BODOQUENA - MS

\section{ZONEAMENTO AMBIENTAL- ZONAS DE PRODUÇÃO}

As zonas ambientais foram divididas conforme Becker e Egler (1996) em duas zonas ambientais e essas por sua vez divididas em seis áreas.

A primeira zona é definida como Zona de Produção, a qual é admitida de acordo com as configurações físico-ambientais da paisagem o desenvolvimento de atividades produtivas que permitam a utilização do potencial natural da paisagem. Essa zona foi dividida em Áreas de Expansão, Áreas de Consolidação e Áreas de Consolidação/ Conservação.

Áreas de Expansão: podem ser utilizadas para a expansão do potencial produtivo, apresentam boa capacidade para desenvolvimento de atividade agrícola, como pecuária, culturas anuais e temporárias, nessas áreas a vulnerabilidade à perda de solos é muito fraca. Nessas áreas a paisagem pode suportar práticas agrícolas com utilização de mecanização, e outros implementos agrícolas, essa classe não representou 1\% da área estudada (Figura 6).

Áreas de Consolidação: o desenvolvimento de atividades produtivas pode ser mantido, apresentam capacidade boa ou regular, para desenvolvimento de atividades agrícolas de ciclos curtos (Figura 7), sem mecanização e pastagem; apresenta fraca vulnerabilidade da paisagem à perda dos solos, essa classe corresponde a $14 \%$ da área estudada (Figura 8).

Áreas de Consolidação/ Conservação: áreas produtivas com restrições de uso, que apresenta características intermediárias entre as zonas produtivas e críticas, essas áreas são inaptas para qualquer tipo de cultura, mas é indicada para uso com pastagem, essa classe é verificada em $7 \%$ da área. Apresenta vulnerabilidade à perda de solos moderada, por isso, necessita de medidas conservacionistas simples para utilização (figura 9). 


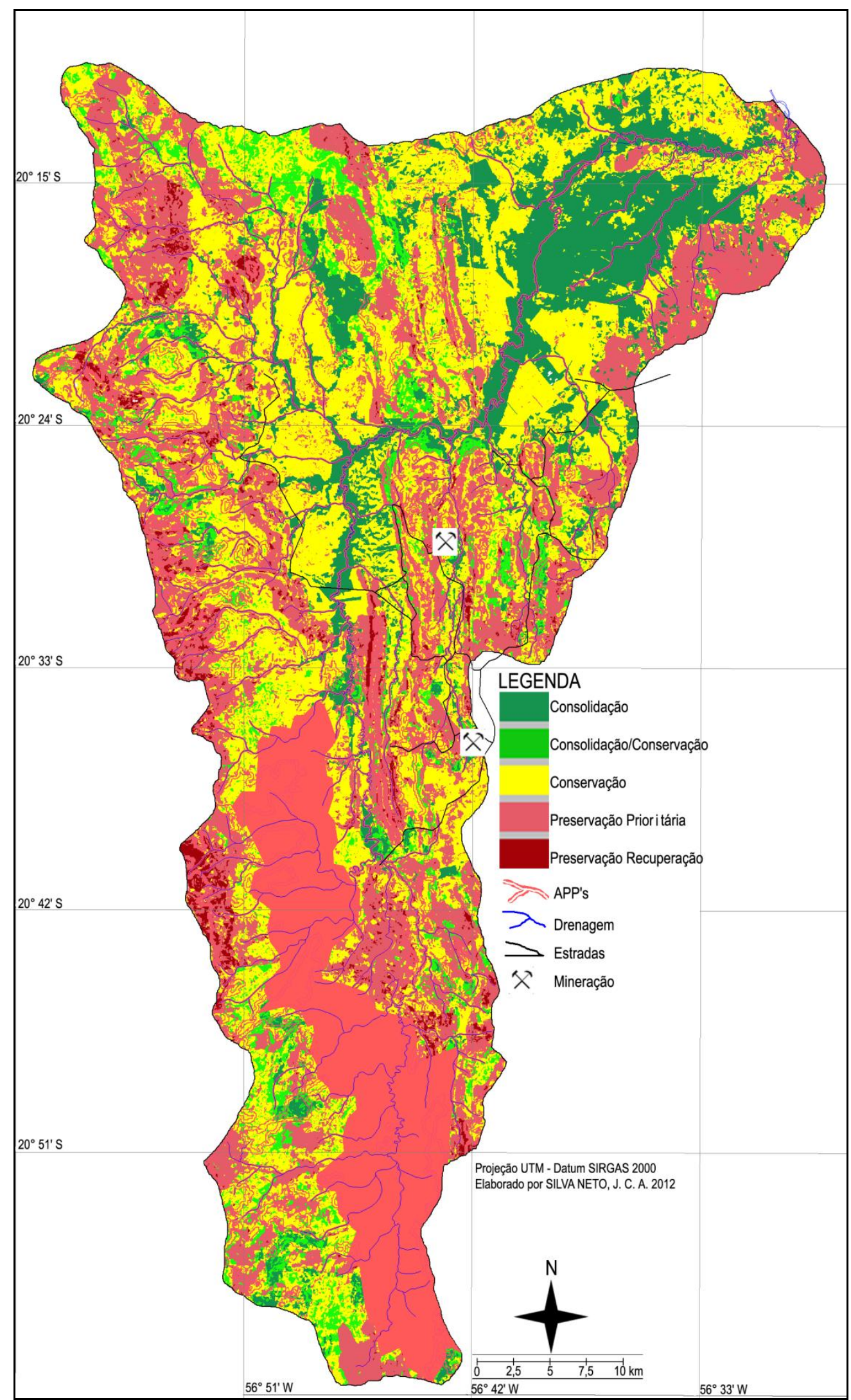

Figura 6: Zoneamento Ambiental da bacia hidrográfica do rio Salobra-MS. 
ZONEAMENTO AMBIENTAL COMO SUBSÍDIO PARA O ORDENAMENTO DO TERRITÓRIO DA BACIA HIDROGRÁFICA DO RIO SALOBRA, SERRA DA BODOQUENA - MS

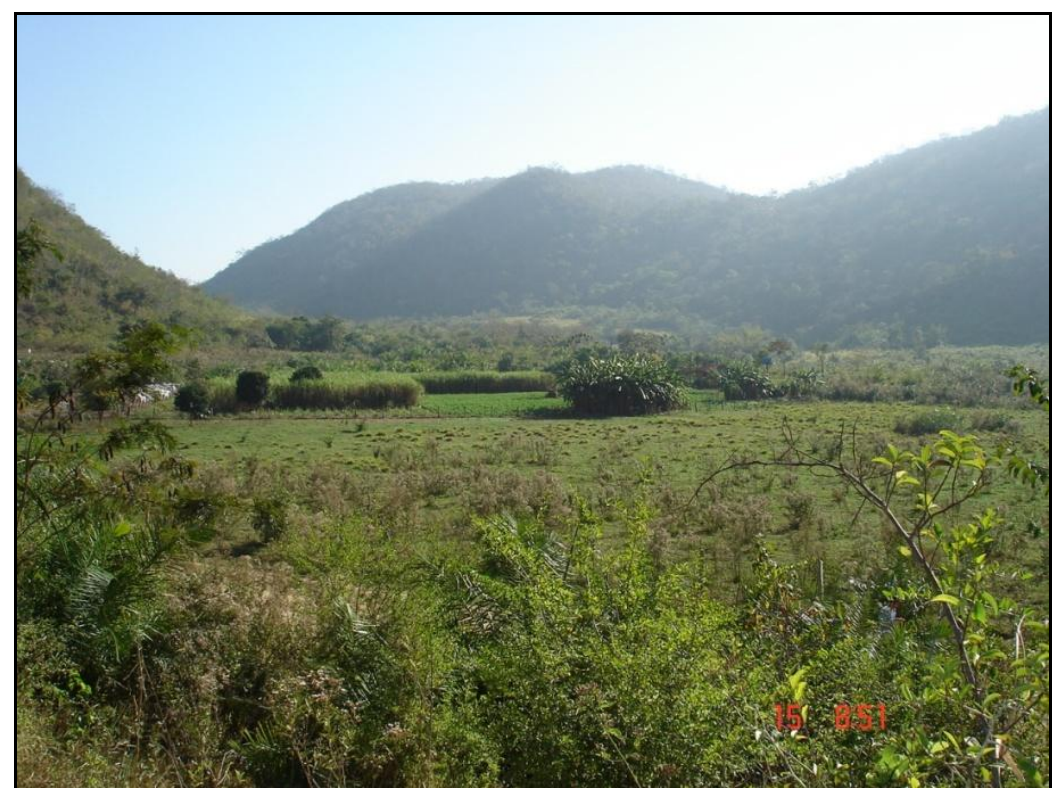

Figura 7: Exemplo de áreas de consolidação, com pequenas culturas de subsistência.

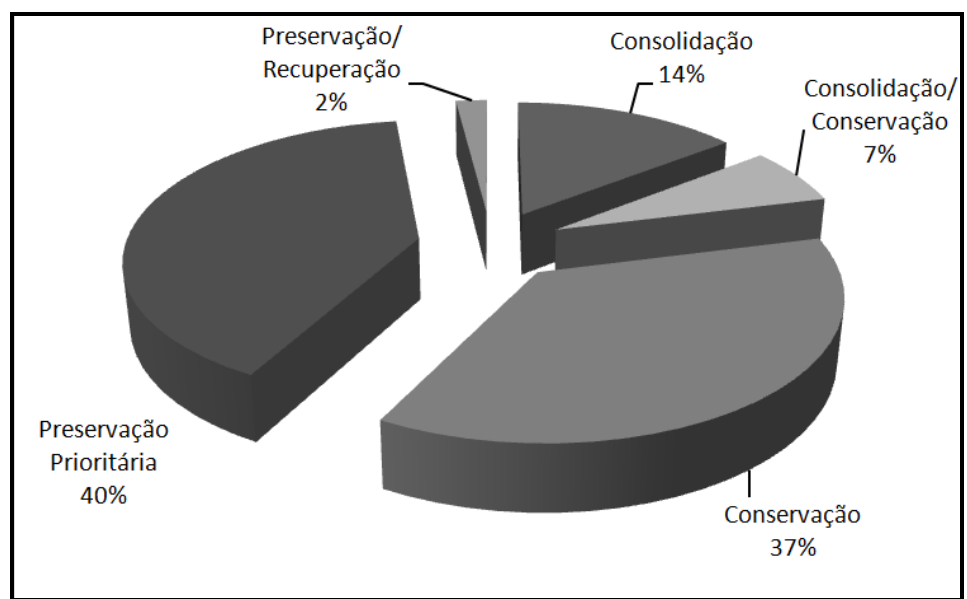

Figura 8: Zoneamento Ambiental na bacia hidrográfica do rio Salobra-MS.

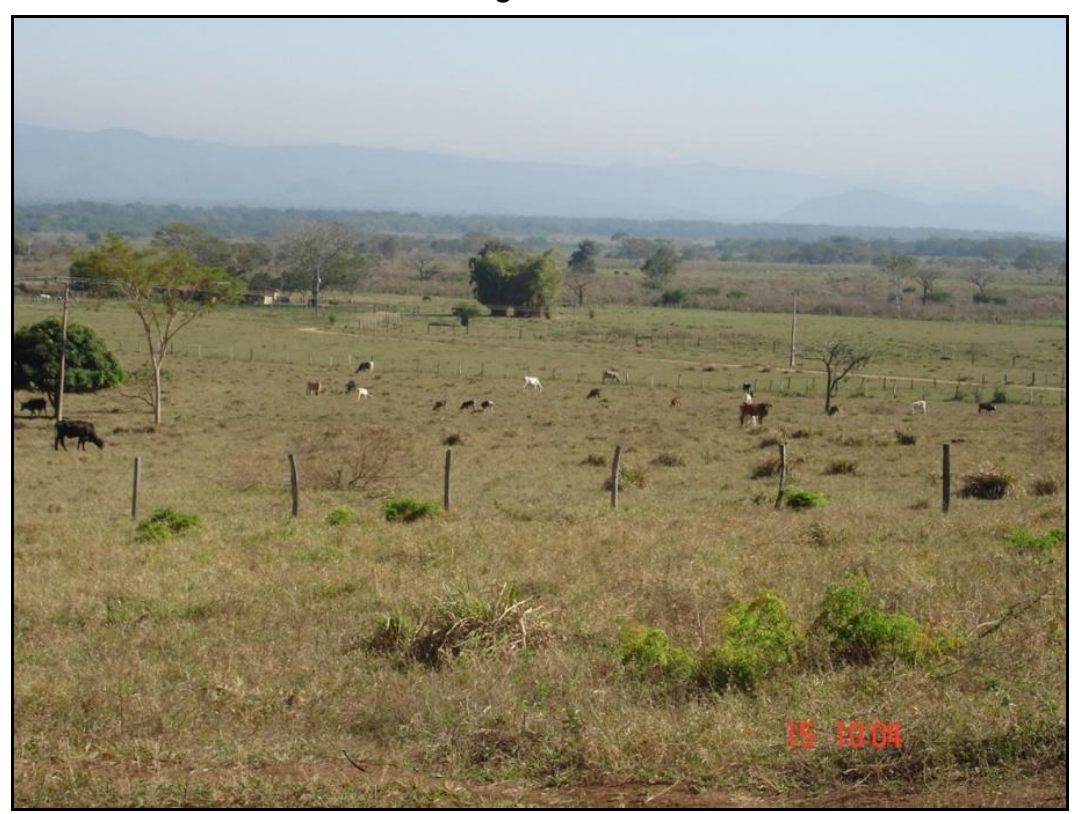

Figura 9: Exemplo de áreas de consolidação/ conservação com pastagem. 
ZONEAMENTO AMBIENTAL COMO SUBSÍDIO PARA O ORDENAMENTO DO TERRITÓRIO DA BACIA HIDROGRÁFICA DO RIO SALOBRA, SERRA DA BODOQUENA - MS

\section{ZONEAMENTO AMBIENTAL- ZONAS CRÍTICAS}

A segunda zona é denominada como Zona Crítica caracterizada por apresentar limitantes físico-ambientais que restringem ou impossibilitam alguns tipos de uso da terra. Essa zona foi dividida em Áreas de Conservação, Áreas de Preservação Prioritária e Áreas de Recuperação/ Preservação.

Áreas de Conservação: apresentam características ambientais de paisagens moderadas vulneráveis, essas áreas exigem utilização racional dos recursos naturais renováveis na perspectiva de bases sustentáveis. No caso de uso direto dessas áreas são exigidas medidas conservacionistas criteriosas. A principal indicação para essas áreas é a conservação, porém, desde que não ocorra em declividades incompatíveis (>20\%) pode ser ocupada por reflorestamento ou pastagem, porém, no caso do uso por pastagem há necessidade de ações rigorosas de conservação. Essa classe foi verificada em $37 \%$ da área total estudada (figura 10).

Figura 10: Exemplos de Areas de Conservação na bacia do Córrego Campina.

Áreas de Preservação Prioritária: são áreas cuja configuração da paisagem exigem proteção a longo prazo. Nelas é inviabilizado qualquer tipo de uso da terra. As áreas de Preservação Prioritária englobam as paisagens com Forte vulnerabilidade à perda de solos e/ou as Áreas de Preservação Permanente (APPs) 
ZONEAMENTO AMBIENTAL COMO SUBSÍDIO PARA O ORDENAMENTO DO TERRITÓRIO DA BACIA HIDROGRÁFICA DO RIO SALOBRA, SERRA DA BODOQUENA - MS

e áreas institucionais como as Unidades de Conservação do Parque Nacional da Serra da Bodoquena que estão inseridas na bacia hidrográfica do rio Salobra, essas zonas correspondem à $40 \%$ de sua área (Figura 11).

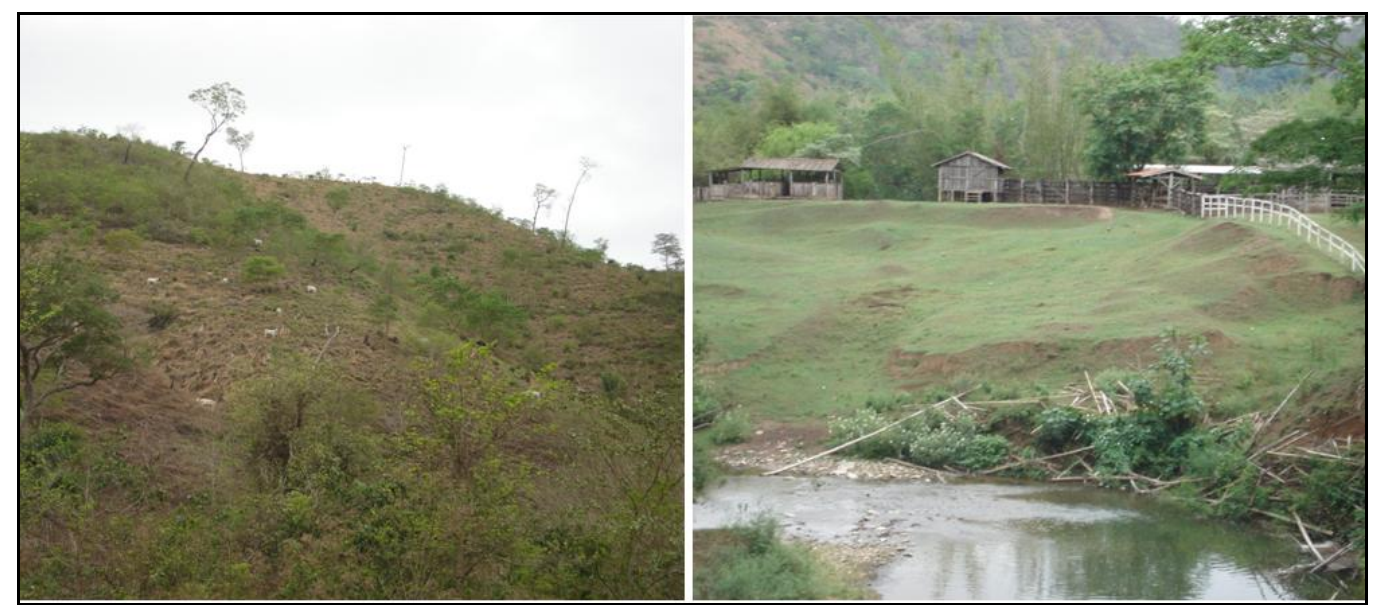

Figura 11: Exemplos de Área de Preservação Prioritária, com desmatamento em áreas com declividade acentuada e em margens de canais de drenagem.

Áreas de Recuperação/ Preservação: são áreas em que o tipo de uso da terra é incompatível com a vulnerabilidade à perda de solos (figura 12), são paisagens que apresentam vulnerabilidade muito forte e caracterizam-se por apresentar uso intenso da terra, como solo exposto ou com usos agrícolas.

Corresponde às áreas que apresentam problemas de degradação dos solos, é indicada para recuperação prioritária, esta área ocupa $2 \%$ da área total da bacia hidrográfica do rio Salobra.

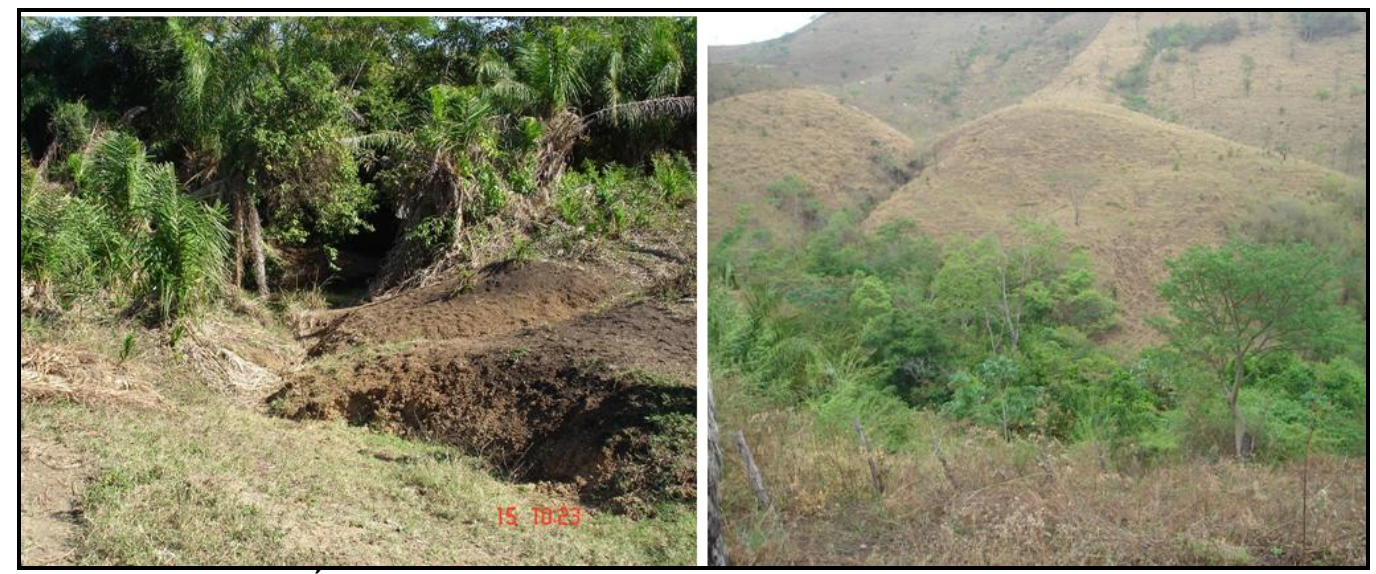

Figura 12: Exemplo de Áreas de Recuperação/ Preservação, observa-se os processos erosivos intensificados em áreas desmatadas. 
Conforme os resultados obtidos, a vulnerabilidade da paisagem à perda de solos representou uma variável de primordial importância na definição das zonas ambientais, as quais foram estabelecidas de acordo com osníveis de vulnerabilidade observada na paisagem da bacia hidrográfica do rio Salobra.

\section{CONSIDERAÇÕES FINAIS}

Entende-se que à medida que as paisagens que apresentam vulnerabilidade forte ou muito forte, sofrem a intensificação no uso da terra, essas paisagens passam do seu estado de estabilidade para o estado de instabilidade, ou seja, à medida que as paisagens vulneráveis sofrem intervenção humana elas aproximamse do processo irreversível de degradação de suas características naturais.

Quanto às ferramentas utilizadas observou-se que os Sistemas de Informações Geográficas contribuíram na otimização do processamento de uma representativa gama de dados, bem como na produção de novas informações, resultado do geoprocessamento.

Nessa perspectiva o zoneamento ambiental da bacia hidrográfica do rio Salobra demonstrou ser um instrumento eficaz para auxiliar o ordenamento do território, caracterizado por abordar as distintas configurações socioambientais, cujo objetivo principal visa definir as transformações, técnicas e ritmos que se adequam a cada lugar segundo suas condições específicas (BECKER E EGLER, 1996).

Com a identificação das diferentes zonas ambientais por meio do zoneamento ambiental, a presente proposta pode auxiliar no estabelecimento de políticas de planejamento e gestão do uso da terra na bacia hidrográfica do rio Salobra.

Nesse sentido a preservação das paisagens vulneráveis da bacia hidrográfica do rio Salobra assume um papel importante no caráter socioeconômico da área, uma vez que o desenvolvimento de atividades econômicas como o turismo, necessita da preservação e conservação das paisagens, cujas comunidades locais residentes nos limites da área estudada podem se beneficiar dessas atividades.

Por fim, destacam-se os resultados analisados, por apresentar uma nova perspectiva para se analisar a bacia hidrográfica do rio Salobra, na qual essas 
ZONEAMENTO AMBIENTAL COMO SUBSÍDIO PARA O ORDENAMENTO DO TERRITÓRIO DA BACIA HIDROGRÁFICA DO RIO SALOBRA, SERRA DA BODOQUENA - MS

informações poderão subsidiar pesquisas futuras, além de auxiliar as políticas publicas para a área.

\section{REFERÊNCIAS}

ALMEIDA, F.F.M. Geologia da Serra da Bodoquena (Mato Grosso), Brasil. Boletim da Divisão de Geologia e Mineralogia, Departamento Nacional de Produção Mineral, Rio de Janeiro, v. 219, p. 1-96, 1965.

ARAÚJO, H.J.T. et al. Geologia. In: BRASIL, Ministério de Minas e Energia Secretária-Geral. Projeto RADAMBRASIL Folha SF-21 Campo Grande (Levantamento de Recursos Naturais, 28). Rio de Janeiro: Ministério de Minas e Energia, Cap.1, p.9-124. 1982.

BECKER, B.K.; EGLER. Claudio Antonio Gonçalves. Detalhamento da Metodologia para Execução do Zoneamento Ecológico-Econômico pelos Estados da Amazônia Legal. Brasília. Secretaria de Assuntos Estratégicos/ Ministério do Meio Ambiente. 1996.

BOGGIANI, P.C. et al. Tufas Calcárias da Serra da Bodoquena. In: SCHOBBENHAUS, C. et. al. (Org.). Indicative List od Geological Sites -. Brasília: GILGES-UNESCO, Cap. 9, p. 249-259. 2000.

CREPANI, E. et al. Zoneamento Ecológico-Econômico. In: FLORENZANO, T.G. (Org.) Geomorfologia: Conceitos e tecnologias atuais. São Paulo: Oficina de Textos, Cap. 10, p. 285 - 318. 2008.

CUNICO, C.; OKA-FIORI, C. Zoneamento ambiental da Bacia Hidrográfica do Rio Marumbi - PR: perspectivas para a análise e avaliação das condições sócioambientais. Estudos Geográficos, Rio Claro, v.6 n.1, p. 37-61, 2008. Disponível em: http://cecemca.rc.unesp.br/ojs/index.php/estgeoAcesso em: 10 de outubro de 2012.

GUIMARÃES, L.J.R.; SANTOS, L.J.C. Levantamento das áreas potenciais à erosão laminar como suporte à detecção das áreas-fonte ao assoreamento na Barragem Piraquara. Revista Eletrônica Geografar, Curitiba, v.2, n.2, p.172-188, 2007. Disponível em: http://ojs.c3sl.ufpr.br/ojs/index.php/geografar/article/view/12106 Acesso em: 10 de outubro de 2012. 
ZONEAMENTO AMBIENTAL COMO SUBSÍDIO PARA O ORDENAMENTO DO TERRITÓRIO DA BACIA HIDROGRÁFICA DO RIO SALOBRA, SERRA DA BODOQUENA - MS

HIDROWEB - Sistema de Informações Hidrológicas, Série histórica de dados de pluviométricos (on-line). Disponível em: http://hidroweb.ana.gov.br Acesso em: 12 de janeiro de 2011.

INSTITUTO NACIONAL DE PESQUISAS ESPACIAIS (INPE): Catálogo de Imagens LANDSAT. Disponível em: http://www.dgi.inpe.br/ Acesso em: 20 de novembro de 2010.

LACERDA FILHO, J.V. et al.Geologia e Recursos Minerais do Estado de Mato Grosso do Sul. Campo Grande: Ministério de Minas e Energia - Serviço Geológico do Brasil. 2006.

LEFF, E. Racionalidade Ambiental: a reapropriação social da natureza. Rio de Janeiro: Editora Civilização Brasileira, 2006.

MELO, J.A.B.; LIMA, E.R.V. Uso da terra, vulnerabilidade e subsídios ao ordenamento territorial em microbacia. Mercator, Fortaleza, v. 11, n. 24, p. 127-148. 2012.

em: http://www.mercator.ufc.br/index.php/mercator/article/view/438/404Acesso em: 9 de julho de 2013.

MESQUITA, C. et al. Vulnerabilidade natural à perda de solos da bacia hidrográfica do Rio Sagrado - Morretes/PR. Revista de Geografia, Recife, v. especial VIII SINAGEO, $\quad \mathrm{n} \quad 2, \quad$ p.249-264. 2010.Disponível em:http://www.revista.ufpe.br/revistageografia/index.php/revista/article/viewFile/347/ $\underline{323}$ Acesso em: 13 de maio de 2013.

NEVES, S.M.A.S. et al.Estimativa da perda de solo por erosão hídrica na bacia hidrográfica do rio Jauru/MT. Revista Sociedade e Natureza. Uberlândia, v. 23, n. 3, p. 423-434, 2011.Disponível em:http://www.seer.ufu.br/index.php/sociedadenatureza/article/view/12535Acesso em: 13 de maio de 2013.

BRASIL, Plano de Conservação da Bacia do Alto Paraguai: Programa Nacional de Meio Ambiente. Brasília: Ministério do Meio Ambiente, dos Recursos Hídricos e da Amazônia Legal. Volumes: I e II, Tomos I e II, 1997.

RODRIGUES, J.B.T. et al. Utilização de Sistema de Informação Geográfica na avaliação do uso da terra em Botucatu- SP. Revista Brasileira de Ciência do Solo, Viçosa, v.25, n. 1, p. 675-681, 2001. Disponível em: http://sbcs.solos.ufv.br/solos/revistas/v25n3a16.pdfAcesso em: 15 de fevereiro de 2010. 
ZONEAMENTO AMBIENTAL COMO SUBSÍDIO PARA O ORDENAMENTO DO TERRITÓRIO DA BACIA HIDROGRÁFICA DO RIO SALOBRA, SERRA DA BODOQUENA - MS

ROSS, J.L.S. Ecogeografia do Brasil: Subsídios para planejamento ambiental. São Paulo: Oficina de Textos, 2006.

SCHIRMER, G.J.; ROBAINA, L.E.S. Zoneamento Geoambiental em municípios do Rio Grande do Sul: município de Agudo. Revista de Geociências, São Paulo, v. 31, n. $1, \quad$ p. 93-102, 2012.Disponível em: http://www.revistageociencias.com.br/31 1/Art08 Schirmer \& Robaina.pdfAcesso em: 9 de julho de 2013.

SILVA, A.M. Potencial natural de erosão no município de Sorocaba, São Paulo, Brasil.Revista Internacional de Desastres Naturales, Accidentes e Infraestructura Civil. Porto Rico, Vol. 8, n.1, 5-14. 2008.Disponível em:http://academic.uprm.edu/laccei/index.php/RIDNAIC/article/view

File/146/142Acesso em: 9 de julho de 2013.

SILVA NETO, J.C.A. Indicação para o uso da terra na Bacia Hidrográfica do Rio Salobra Serra da Bodoquena, Mato Grosso do Sul.RA'E GA: o Espaço Geográfico em Análise, Curitiba, v. 25, p. 279-304,2012. Disponível em: http://ojs.c3sl.ufpr.br/ojs-2.2.4/index.php/raega/article/view/28014 Acesso em: 9 de julho de 2013.

OLIVEIRA, P.T.S. et al. Processo Analítico Hierárquico aplicado a vulnerabilidade natural à erosão. Revista de Geociências, São Paulo, v. 28, n. 4, p. 417-424, 2009.Disponível

em:http://www.revistageociencias.com.br/28 4/Art\%2006 Oliveira.pdf Acesso em: 9 de julho de 2013.

THOMAS, B.L. Proposta de zoneamento ambiental para o município de Arroio do Meio - RS. RA'E GA: o Espaço Geográfico em Análise, Curitiba, 24, p. 199-226, 2012. Disponível em:http://ojs.c3sl.ufpr.br/ojs2.2.4/index.php/raega/article/view/26215Acesso em: 9 de julho de 2013.

VALLEJO, L.R. Os parques e reservas como instrumentos do ordenamento territorial. In: ALMEIDA, F.G.; SOARES, L.A.A. (org.). Ordenamento Territorial: Coletânea de textos com diferentes abordagens no contexto brasileiro. Rio de Janeiro: Bertrand Brasil, 2009. 